\title{
2. CHOOSING THE TEACHING CAREER BY STUDENTS IN THE ARTS
}

Ona Ionica Anghel 265

\begin{abstract}
In order to build strategies for the permanent improvement of the educational offer in higher education institutions, taking into account the expectations of the beneficiaries can be an important direction to consider. Thus, the present study aims to radiograph the reasons why the students of the National University of Arts "George Enescu" in Iași (UNAGE) also choose a training trajectory for the route of the teaching career. To achieve this objective, we used in our research the linguistically adapted questionnaire "Orientations for Teaching Survey - OTS" (Ferrell, C.M., Daniel, L.G, 1993), which was answered by 140 UNAGE students. The hypothesis that the reasons why these students prepare to become teachers are intrinsic, extrinsic and altruistic was confirmed by statistical analyzes.
\end{abstract}

Key words: career motivation, teaching career, motivational types

\section{Preliminaries}

The arts are a field that allows easier than any other holistic formation and education of the pupil: mind, feeling, power of action, spirit. Thus, the art teachers have not only the responsibility of transmitting the knowledge to their students and training them the practical skills specific to the good expression in the technique of each art, they especially have the responsibility to train people who will be able to express themselves in a balanced way, to understand and manifest in outside what they feel, think and do in beautiful manners. We, the trainers of these future art teachers, want to make visible to them the responsibility of their profession and we are constantly looking for ways to do so. In the desire to improve the quality of the programs we offer, on the occasion of the present study, we ask ourselves what is the motivation in choosing the training route for a teaching career of students of the arts?

In the European space, there have been multiple studies aimed at identifying the reasons why students choose to train in their teaching career (Johnston, J., 1999, Heinz, M. 2015, Kyriacou, C., 1999, Heinz, M. 2015). These studies have shown that we can consider three broad categories of such reasons: intrinsic, extrinsic and altruistic. The intrinsic motives cover aspects of the teaching profession itself, such as teaching activity or interest in using one's own scientific training to train students, but also personal self-development and work in the school environment. The extrinsic reasons cover aspects of the teaching profession that are not directly related to it, such as the teacher's program, or payment, but also the material benefits or security offered by this profession. The altruistic motives cover aspects related to the special pleasure of working with

265 Lecturer PhD., "George Enescu” National University of Arts from Iaşi, Romania, email: ona_anghel@yahoo.com 
students, their desire to contribute to the evolution of the students, or to the help given to society for progress (Moran, A., 2001).

\section{Research methodology}

To reach the proposed purpose, to investigate the reasons why students from two faculties of George Enescu University of Arts, Iasi (Faculty of Musical Interpretation, Composition and Theoretical Studies, as well as the Faculty of Visual Arts and Design) and who are enrolled in the psycho-pedagogical module choose the teaching career, we have followed three steps, equivalent of the three objectives:

- identification of the main reasons that give rise to the intention of training in the teaching career of students of arts;

- comparison of the reasons why the students from the two faculties chose the training for the teaching career;

- identification of motivational profiles regarding the choice of teaching career depending on the level of preparation (bachelor's or master's degree) and gender.

We want to verify the hypothesis that the orientation in the teaching career of the students enrolled in the psycho-pedagogical training modules is due to both altruistic, extrinsic and intrinsic reasons.

The research instrument used is the "Orientations for Teaching Survey OTS" questionnaire, built in 1993 by Ferrell, C.M. and Daniel, L.G. - taken from the article published by Moran, A., 2001, and then linguistically adapted for the Romanian language according to all statistical norms (Anghel, 2006). "Orientations for Teaching Survey - OTS" is an instrument made up of 58 items organized on eight scales: "love for children" and "desire to serve society" measure altruistic motives, "feeling of vocation for the teaching profession" and "intellectual challenge" it measures the intrinsic motives, "favorable working conditions", "the status of the teacher and the desire to be an authority", "influence from others", "aspects related to training for this profession" measures the extrinsic reasons.

The group of subjects on which the investigation was carried out consists of 140 students of the National University of Arts "George Enescu" in Iași as follows: 73 students in Visual Arts and Design, 67 students in the Faculty of Musical Interpretation, Composition and Theoretical Studies; 90 students enrolled in undergraduate studies (level I of training in teaching career) and 50 students enrolled in masters studies (level II of training in teaching career); 92 female subjects and 48 male subjects. In order to reach the proposed objectives and to verify the hypothesis launched, we used to process the data obtained through the questionnaire, using the SPSS 20 program. As methods of statistical processing we used (Lungu, 2000, and Pallant, 2001):

- analysis of the sum at the elections received by each of the 58 reasons (OTS items) - for the outline of a motivational portrait of the orientation towards the didactic career of the investigated subjects; 
- differentiated comparison test for quantitative variables, Independent Samples $\mathrm{T}$ Test - to identify motivational profiles based on: faculty specificity (music, visual arts); the level of psycho-pedagogical training (level I, level II) and gender function (female, male) regarding the choice of teaching career by the investigated subjects.

\section{The results of the study}

We obtain extremely interesting information after the statistical processing of the results. Thus, the first 10 reasons that explain the choice of teaching career are intrinsic or altruistic in nature, students being stimulated by the opportunity to work with children and young people, to help them in increasing confidence in their own strengths but also in a challenging job that allows you to you share knowledge with others, so to affirm yourself, a job in which you can manifest your creativity. Here are the gross results for the most and least chosen reasons:

a) The most chosen reasons:

\begin{tabular}{|c|l|c|}
\hline Rank & \multicolumn{1}{|c|}{ Item / Reason } & $\begin{array}{c}\text { Sum on } \\
\text { each item }\end{array}$ \\
\hline 1 & $\begin{array}{l}\text { q8: teaching gives me an opportunity to help students gain a sense of } \\
\text { achievement and self-worth. }\end{array}$ & 608 \\
\hline 2 & q17: it is an intellectually stimulating occupation. & 594 \\
\hline 3 & q 1: I would like to work with young people. & 592 \\
\hline 4 & q 30: I have a desire to impart knowledge to other people. & 585 \\
\hline 5 & $\begin{array}{l}\text { q 37: teaching gives me a chance to serve as a positive role model for } \\
\text { children. }\end{array}$ & 584 \\
\hline 6 & q 18: teaching is a fulfilling and challenging occupation. & 581 \\
\hline 7 & q 33: teaching is a creative profession. & 570 \\
\hline 8 & q53: teaching gives me a lifelong opportunity to learn. & 568 \\
\hline 9 & q7: teaching gives me a chance to help the less fortunate & 566 \\
\hline 10 & $\begin{array}{l}\text { q26: I love children. } \\
\text { q55: teaching gives me a chance to be my own boss. }\end{array}$ & 560 \\
\hline
\end{tabular}

b) The least chosen reasons:

\begin{tabular}{|c|l|c|}
\hline Rank & \multicolumn{1}{|c|}{ Item / Reason } & $\begin{array}{c}\text { Sum on } \\
\text { each item }\end{array}$ \\
\hline 54 & $\begin{array}{l}\text { Q16: it is less expensive to prepare to teach than to prepare form any } \\
\text { other fields. }\end{array}$ & 302 \\
\hline 55 & $\begin{array}{l}\text { Q46: I was told about a scholarship or tuition reimbursement } \\
\text { program available to persons entering eacher education } \\
\text { programmers. }\end{array}$ & 291 \\
\hline 56 & Q39: teaching is a tradition in my family. & 276 \\
\hline 57 & Q43: I trained for another field but could not get a job. & 256 \\
\hline 58 & $\begin{array}{l}\text { Q44: I trained for another field but did not feel comfortable in that } \\
\text { field. }\end{array}$ & 242 \\
\hline
\end{tabular}

Viewing the 8 scales helps us to have an overview of the general 
motivational profile regarding the choice of teaching career by students from the arts (Graph 1). We can thus see that the teaching profession is chosen mainly because it is challenging. It also brings us once again evidence that altruistic and internal motives prevail over external ones.

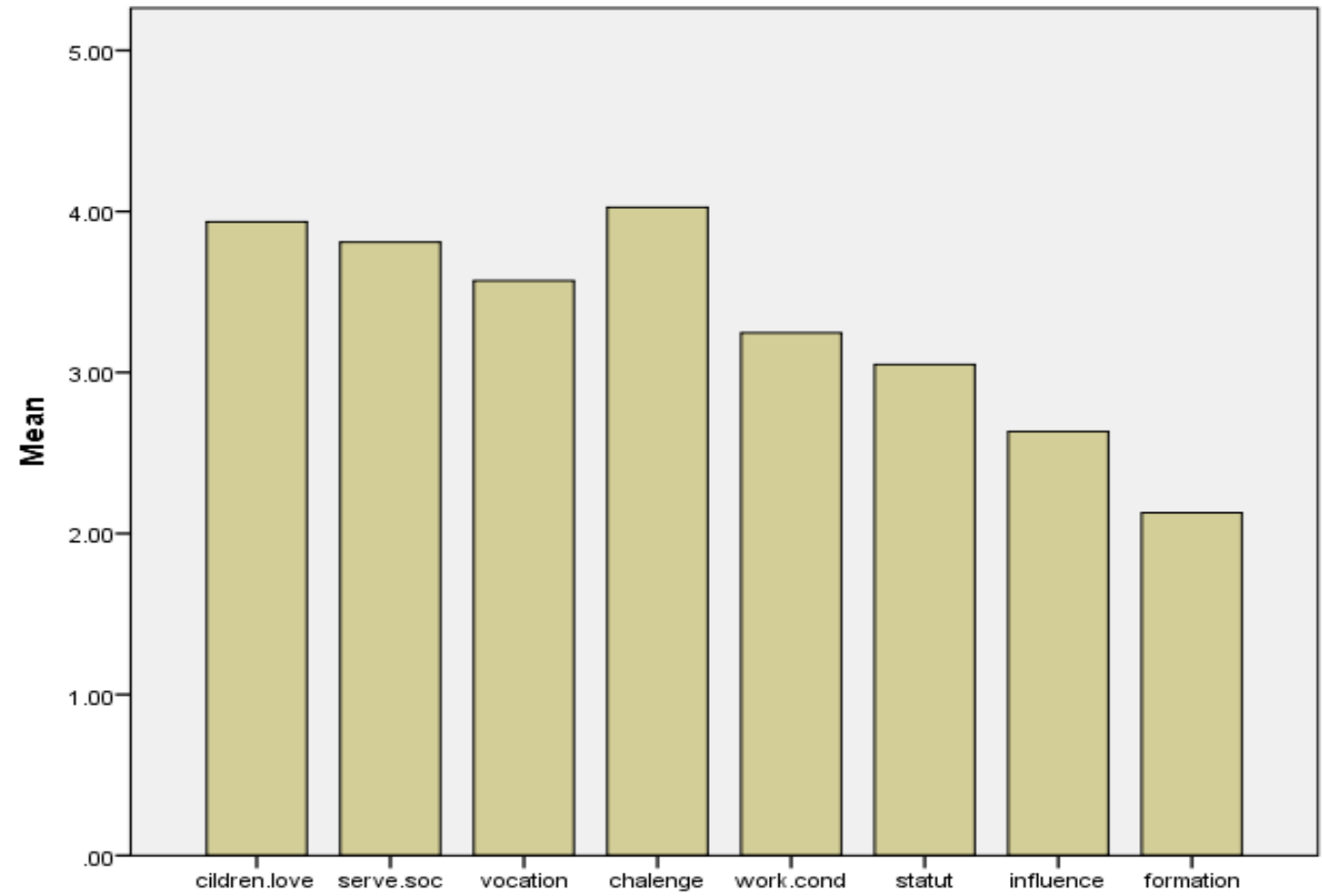

Graph 1: Average of the responses on the scales

Regarding the second and third objective, in which we wanted to find out if there are significant differences regarding the reasons for career orientation between the compared groups, the statistical processing of the data showed us that they are quite small:

- on a single item we identified significant differences given by the faculty profile, so the students from music choose more than those from the visual arts item 3 of the questionnaire: "I feel good in the school environment" $(\mathrm{t}(138)=$ 2.98 , for the significance threshold $\mathrm{p}=.03$ and $\mathrm{M}$ visual arts average $=3.43$, Music $=4.02$ );

- we identified several areas with significant differences depending on the level of preparation of the students, the average of those of level I being lower than those of level II for the following items:

- Item 1 (I would love to work with teenagers or young people): $\mathrm{t}(3.19)=134$, $\mathrm{p}=.002, \mathrm{M}(4.04 ; 4.54)$;

- Item 2 (Allows me to perform a social service with moral value): $\mathrm{t}(3.88)=122$, $\mathrm{p}=.001, \mathrm{M}(3,41 ; 4.52)$;

- Item 20 (I want to solve some of the problems facing the education system): $\mathrm{t}$ $(2.55)=120, \mathrm{p}=.012, \mathrm{M}(3.71 ; 4.26)$;

- Item 41 (Gives me the chance to promote respect for knowledge and learning.): $\mathrm{T}(3.21)=125, \mathrm{p}=.002, \mathrm{M}(3.72 ; 4.35)$. 
- we identified 3 items with significant differences determined by gender, the average girls being slightly higher than the boys:

- Item 20 (I want to solve some of the problems that the education system is facing.): $\mathrm{T}(1,01)=79, \mathrm{p}=.03, \mathrm{M}(4.01 ; 3.77)$;

- Item 31 (gives me the chance to influence society): $\mathrm{t}(0.80)=82, \mathrm{p}=.04, \mathrm{M}$ $(3.76 ; 3.58)$;

- Item 34 (As a teacher I have the opportunity to enjoy extracurricular activities.):

$\mathrm{T}(1.54)=79.7, \mathrm{p}=.02, \mathrm{M}(3.69 ; 3.33)$.

\section{Conclusions}

This study brings to our attention once again the complexity of the career orientation process and especially the complexity of choosing the teaching profession as a career for students who have as their first choice the artistic specialization.

We started the investigation from the results of other research that have sedimented the reality that young people who choose to train to become teachers are intrinsically motivated, extrinsically motivated, or driven by altruism. The results proved that our starting hypothesis was true, without significant differences neither according to gender, nor according to the artistic specialization nor the level of preparation for the teaching career. However, the present study showed that the students who answered the questionnaire are guided in the choice of the teaching career, especially for altruistic or intrinsic reasons. The desire to give students confidence in their own strength and the possibility of being positive role models for students (whether they benefited from model teachers or not, were not satisfied by some teachers and want to counteract those negative examples) are the reasons the highest levels of intensity. Likewise, promoting respect for knowledge and learning or opportunities for self-development (of personality and intellect) are among the top reasons. These aspects can only delight us. Having future teachers with such attitudes, the quality of the educational process they will set in motion, will certainly be a high one.

The data obtained determine us for further research. Investigating the motivational differences regarding the orientation towards the teaching career that appear between students preparing to teach artistic disciplines and students preparing to teach general disciplines.

\section{References}

1. Anghel, O., 2006, Choosing the Didactic Career by the Polytechnic University Students, (Alegerea carierei didactice de către studenţii politehnişti), Teacher Education and Training Department Bulletin. 9: 110-116, "Al. I. Cuza" University Publishing House. 
2. Johnston, J., 1999, Choosing Primary Teaching as a Career: the perspectives of males and females in training, Journal of Education for Teaching. 25 (1): 5564.

3. Heinz, M., 2015, Why Choose Teaching? An International Review of Empirical Studies Exploring Student Teachers' Career Motivations and Levels of Commitment to Teaching, Educational Research and Evaluation. 21 (3): 258297.

4. Kyriacou, C., 1999, Student Teachers' Motivation to Become a Secondary School Teacher in England and Norway, Teacher Development. 3(3): 373-381.

5. Kyriacou, C., 2002, Moroccan foreign language students' views of a career in teaching, Journal of Educational Enquiry. 3(2): 84-95.

6. Lungu, O., 2000, Getting Started Guide for SPSS-10.0 (Ghid introductiv pentru SPSS-10.0), “Al. I. Cuza" University Publishing House.

7. Moran, A., Kilpatrick, R., Abbott, L, Dallat, J., McClune, B., 2001, Training to Teach: Motivating Factors and Implications for Recruitment, Evaluation and Research in Education. 15(1): 17-32.

8. Pallant, J., 2001, SPSS Survival Manual, Swinburne Unuversity Press, Australia. 